\title{
Physical Properties of Macroporous Tungsten Oxide Thin Films and Their Impact on the Photocurrent Density
}

\author{
I. Riech, ${ }^{1}$ M. Acosta, ${ }^{1}$ M. A. Zambrano-Arjona, ${ }^{1}$ F. Peñuñuri, ${ }^{1}$ M. Rosado-Mendoza, ${ }^{1}$ \\ E. Marín, ${ }^{2}$ P. Rodríguez-Fragoso, ${ }^{3}$ and J. G. Mendoza-Álvarez ${ }^{3}$ \\ ${ }^{1}$ Laboratorio de Ciencia de Materiales, Facultad de Ingeniería, Universidad Autónoma de Yucatán, 97130 Mérida, YUC, Mexico \\ ${ }^{2}$ Instituto Politécnico Nacional, Centro de Investigación en Ciencia Aplicada y Tecnología Avanzada, Unidad Legaría, Legaria 694, \\ Colonia Irrigación, 11500 México, DF, Mexico \\ ${ }^{3}$ Departamento de Física, CINVESTAV-IPN, A.P. 14-740, 07000 México, DF, Mexico
}

Correspondence should be addressed to I. Riech; ines.riech@uady.mx

Received 9 July 2013; Accepted 1 September 2013

Academic Editor: David Lee Phillips

Copyright (C) 2013 I. Riech et al. This is an open access article distributed under the Creative Commons Attribution License, which permits unrestricted use, distribution, and reproduction in any medium, provided the original work is properly cited.

\begin{abstract}
Tungsten trioxide $\left(\mathrm{WO}_{3}\right)$ films were prepared using polystyrene spheres of two different diameters as a template in order to create porous layers. X-ray diffraction data and electron microscopy images show that annealed films exhibit polycrystalline structure with monoclinic phase and pore size of approximately hundred nanometers. The optical band gap energies have been determined by photoacoustic spectroscopy as $3.17 \mathrm{eV}$, and this value was not affected by sample morphology. Low temperature photoluminescence spectra exhibit broad band in the blue region. Deconvolutions of PL spectra show that there are two transitions which intensity depends on thin film pore size. We discuss the possible origin of this emissions associated with oxygen vacancies and surface states. A comparative study of the $\mathrm{WO}_{3}$ films used as photoanodes is presented and correlated with PL results.
\end{abstract}

\section{Introduction}

Among transition metal oxides, tungsten trioxide $\left(\mathrm{WO}_{3}\right)$ has been extensively investigated due to its structural and physical properties. The experimental evidence of advantages of using porous films in a great variety of devices has been reported by several authors [1-3]. Such films are suitable for those applications where large effective surface area is needed to enhance the contact between an electrode and electrolyte, as in the case of photoelectrochemical cells, or between thin film and absorbed gas, as in the case of gas sensors. Taking into account the pore size, materials are classified as microporous, mesoporous, and macroporous. Most of the reported papers are about the study of WO3 thin films with porous size smaller than $50 \mathrm{~nm}$ (micro- and mesoporous). Less attention have been paid to macroporous tungsten oxide films, despite they have a wider range of potential applications as an ion hosting material in electrochromic devices [4-6], chemical sensing [7], or photocatalysts [8]. According to the literature reports, the syntheses of the material and its morphological and structural properties have been investigated in much greater detail than electronic properties. However, in many applications, such as photocatalytic, it is important to control recombination centers which limit the efficiency by the quick recombination of photogenerated carriers through it.

To prepare $\mathrm{WO}_{3}$ thin films, several preparation techniques have been used: sol-gel [9], chemical vapor deposition [10], and radio frequency (RF) sputtering [11], among others. The sol-gel technique has advantages over other deposition techniques because it provides low temperature growth and low cost. One of the methods to obtain porous thin films by sol-gel technique is based on templating strategy which implies sol-gel synthesis, either within the porous of a membrane or around polystyrene spheres [4].

In the present study, we have obtained macroporous tungsten oxide films by sol-gel with two different porous sizes using polystyrene microspheres (PS) as a template. We investigated the relationship between morphological and physical properties of these porous layers, and we compared them, for reference, with those of a compact layer grown 
in similar conditions. To evaluate the optical properties as a function of thin film morphology, photoacoustic (PA) and photoluminescence (PL) spectroscopy were used.

One of the advantages of the PA spectroscopy (PAS) technique in this case is its less sensitivity to light scattering effects, which are present in porous materials with the consequent difficulty to obtain information about their optical absorption. The PA signal is generated by sample heating during the absorption of intensity modulated light in a gas enclosed with the sample in the PA chamber, becoming a noninvasive and contactless method. In previous work photothermal techniques have been applied to determine optical band gap and thermal properties of nonporous $\mathrm{WO}_{3}$ thin films [12,13]. On the other hand, the photoluminescence (PL) technique is well known as a technique which allows the detection of radiative transition processes [14]. PL spectra of $\mathrm{WO}_{3}$ thin films measured at room temperature have been reported previously, but only few authors as Parachini and Schianchi reported PL spectra of $\mathrm{WO}_{3}$ films measured at low temperature [15].

In this work, we applied PA and low temperature PL techniques to evaluate electronic transition processes of porous thin films and reported the correlation between pore size and optoelectronic properties, in particular, the study of band gap and subbandgap recombination.

\section{Experimental Details}

2.1. Samples Preparation. Tungsten oxide thin films were grown on glass Corning 1737 coated with Indium Tin Oxide (4-10 $\Omega$ sheet resistance) using a sol-gel spin-coating technique. The substrates were ultrasonically cleaned with distilled water, acetone, and isopropanol, and then they were dried at room temperature. Anhydrous tungsten hexachloride $\mathrm{WCl}_{6}$ (Aldrich 99.9\%) was used as the precursor and isopropanol (J.T.Baker 99.92\%) as the solvent. The solution was prepared dissolving $2 \mathrm{~g}$ of $\mathrm{WCl}_{6}$ in $20 \mathrm{~mL}$ of isopropanol in constant stirring at room temperature in air. The color of the solution was orange; it immediately turned into a deep-yellow color, and after 15 minutes it changed to a deepblue color. One hour later, polyethylene glycol (PEG) was added with a molecular weight of 200 as a structure-directing agent. A molar ratio of PEG to $\mathrm{WO}_{3}$ of 1 was used. Two types of porous films were prepared adding $0.5 \mathrm{~mL}$ of $2.5 \%$ solid aqueous suspension of polystyrene spheres (PS) of 0.1 and $0.5 \mu \mathrm{m}$ of diameter, respectively. Additionally, the sample without PSs was prepared for a comparative purpose. Thin films were prepared by spin-coating a drop of the solution on the substrate. All the as-grown films were annealed for 2 hours at $500^{\circ} \mathrm{C}$ in air in order to remove the organic template. Films were crack free and strongly adherent to the substrate. Three types of samples were prepared for the present study, compact $\mathrm{WO}_{3}$ layer for reference (sample $\mathrm{A}$ ) and porous $\mathrm{WO}_{3}$ thin film obtained using polystyrene spheres of $0.1 \mu \mathrm{m}$ (B) and $0.5 \mu \mathrm{m}(\mathrm{C})$ of diameter.

2.2. Characterization Techniques. The structural properties of the films were obtained using X-ray diffraction (XRD) on a
Siemens D500 diffractometer equipped with $\mathrm{Cu} \mathrm{K} \alpha$ radiation $(\lambda=0.154 \mathrm{~nm})$. XRD data of the films were examined by a grazing angle of 30 with a step of 0.020 , integrating $10 \mathrm{~s}$ in each step. Films were also characterized by scanning electron microscopy (SEM) and energy dispersive spectroscopy (EDS) in a Philips XL-30 ESEM microscope. Transmittance spectra were recorded with the help of an Agilent 8453 UV-Vis spectrophotometer. Film thicknesses were measured using a profiler VeecoDektak 8 Stylus, and a main value of ( $1 \pm$ $0.1) \mu \mathrm{m}$ was found.

PAS spectra were recorded using a conventional homemade PA system. The light coming from a Xenon arc lamp (ORIEL 66924 operated at $900 \mathrm{~W}$ ) passed through a monochromator (ORIEL Cornerstone $1301 / 8 \mathrm{~m}$ ) with 1200 lines $/ \mathrm{mm}$ diffraction grating in order to obtain monochromatic light in the $250-1200 \mathrm{~nm}$ spectral range, modulated with a mechanical chopper (Oriel 75159). The modulation frequency was fixed at low frequency $(17 \mathrm{~Hz})$ in order to ensure high PA signal amplitude and fulfill the thermally thin sample condition. The monochromatic and modulated beam was focused on the sample located inside the PA cell chamber. An electret microphone connected to the cell through a narrow channel recorded the PA signal, which was measured by a Lock in amplifier (SR-850). PA spectra were normalized using carbon black as a reference sample in the usual way. Photoluminescence spectra of $\mathrm{WO}_{3}$ thin films were obtained at $15 \mathrm{~K}$, by using a $\mathrm{He}-\mathrm{Cd}$ ion laser as a light source with an excitation wavelength of $325 \mathrm{~nm}$ and a power of $35 \mathrm{~mW}$.

In order to estimate the sample's thermal diffusivity, which is necessary for the interpretation of PA spectra as we will see below, we carried out photothermal radiometry (PTR) measurements. A modulated laser diode with $630 \mathrm{~nm}$ wavelength was used to generate the photothermal effect. The blackbody radiation from the optically excited sample was collected using two off-axis parabolic mirrors (Edmund Optics), and it was focused onto a liquid-nitrogen-cooled HgCdTe (Mercury-Cadmium-Telluride) detector (EG\&G Judson J15D12-M204-S4) with an active square size area of $4 \mathrm{~mm} \times 4 \mathrm{~mm}$ and a spectral bandwidth of $2-12 \mu \mathrm{m}$. An antireflection-(AR-) coated germanium window with a transmission bandwidth of 2-14 $\mu \mathrm{m}$ was mounted in front of the detector to block any visible radiation from the laser. Before being sent to the digital lock-in amplifier (Stanford Research System Model SR850), the photothermal radiometric signal was amplified by a preamplifier with a frequency bandwidth 5-1 MHz (EG\&G Judson Model PA-101), especially designed for operating the HgCdTe detector. The theory of the PTR measurement for thermal diffusivity estimations is presented further in Section 3.2.

The photocurrent response of $\mathrm{WO}_{3}$ thin films was measured using a standard three-electrode photoelectrochemical cell. $\mathrm{WO}_{3}$ samples were used as photoanodes, with an exposure area of $1.0 \mathrm{~cm}^{2}$. A platinum foil was used as a counter electrode and $\mathrm{Ag} / \mathrm{AgCl}_{2}$ as a reference electrode. The electrodes were immersed in $0.5 \mathrm{M} \mathrm{Na}_{2} \mathrm{SO}_{4}(\mathrm{pH}$ 4). The photoanodes and the counter electrode were separated by a fine porous glass filter to prevent the recombination of hydrogen and oxygen molecules. The solar spectrum was 


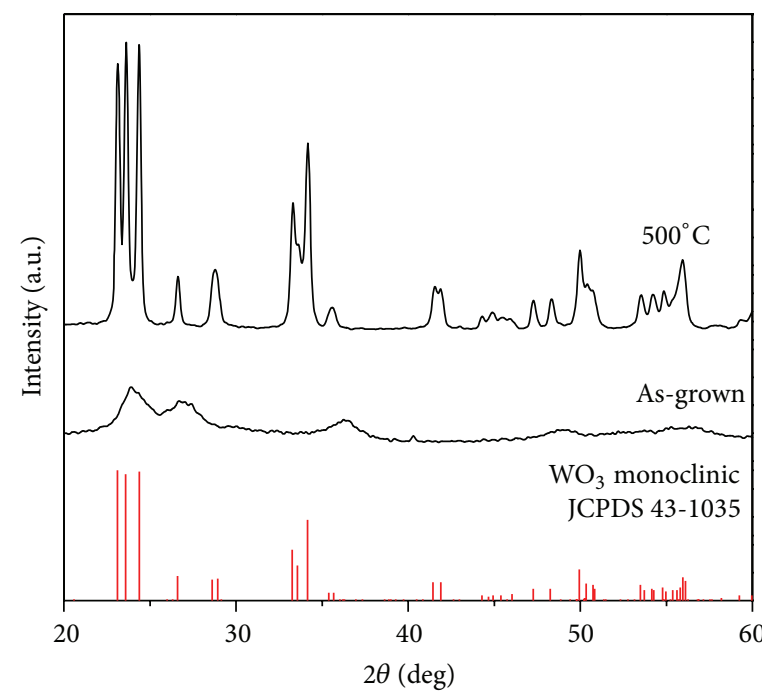

(a)

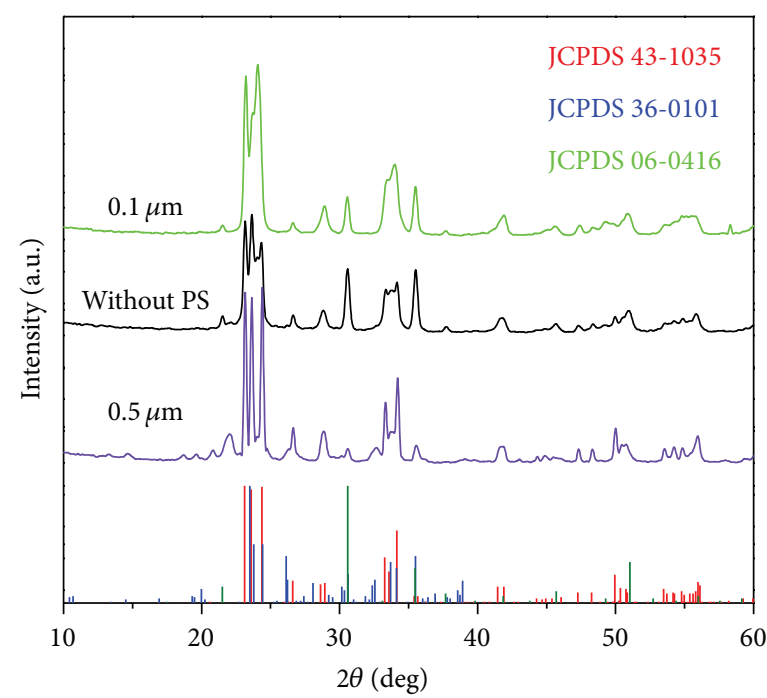

(b)

FIGURE 1: XRD patterns for (a) powder samples before and after annealing at $500^{\circ} \mathrm{C}$ and (b) for obtained annealed films.

TABLE 1: Properties of sol gel prepared $\mathrm{WO}_{3}$ thin films.

\begin{tabular}{cccc}
\hline Sample identification & $\begin{array}{c}\text { Crystallite size } \\
\mathrm{nm}\end{array}$ & Morphology \\
\hline $\mathrm{A}$ & Compact layer & 20 & \\
\hline $\mathrm{B}$ & $\begin{array}{c}\text { Porous layer } \\
(\text { PS diameter: } 0.1 \mu \mathrm{m})\end{array}$ & 20 & $\begin{array}{c}\text { Spherical particles } \\
(110-130 \mathrm{~nm})\end{array}$ \\
\hline $\mathrm{C} \quad \begin{array}{c}\text { Porous layer } \\
(\text { PS diameter: } 0.5 \mu \mathrm{m})\end{array}$ & 23 & $\begin{array}{c}\text { Spherical particles } \\
(600-800 \mathrm{~nm})\end{array}$ \\
\hline
\end{tabular}

simulated using a xenon lamp. The photocurrent density was measured using a potentiostat/galvanostat.

\section{Results and Discussions}

3.1. Morphology and Structural Properties. Powdery samples were prepared from sol in order to perform XRD analysis. The XRD pattern shown in Figure 1(a) indicates that powders present only weak (100) and (101) diffraction peaks that correspond to monoclinic $\mathrm{WO}_{3}$ (JCPDS 43-1035) phase [16]. After the powders annealing at $500^{\circ} \mathrm{C}$, the intensity of the monoclinic $\mathrm{WO}_{3}$ peaks increased considerably. The XRD pattern for as-grown films only shows the peaks from the substrate identified as $\mathrm{In}_{2} \mathrm{O}_{3}$ (JCPDS 06-0416) [16].

Figure 1(b) shows XRD data corresponding to $\mathrm{WO}_{3}$ thin films after annealing at $500^{\circ} \mathrm{C}$. Films $\mathrm{A}$ and $\mathrm{B}$ only exhibited the peaks of monoclinic $\mathrm{WO}_{3}$ phase, while the film $\mathrm{C}$ crystallized into a combination of monoclinic $\mathrm{WO}_{3}$ (JCPDS 43-1035) and $\mathrm{W}_{18} \mathrm{O}_{49}$ (JCPDS 36-0101) phases. The crystallite sizes were determined using the Scherrer's equation [17]. The obtained values are shown in Table 1.
Figure 2 shows SEM images of the surfaces of B and C films before and after annealing at $500^{\circ} \mathrm{C}$. In general, asgrown samples consisted of agglomerated nanoparticles. By annealing at $500^{\circ} \mathrm{C}$, the formation of well-defined grains with dimensions of hundreds of nanometers can be seen. Comparing the surface morphology of the films, it can be observed that as-grown films were formed by cluster of materials, and after the annealing, rounded regions influenced by the PS removed were obtained. The diameter of the PS used as sacrificed templates was found to influence the morphology of the resulting thin films (see Table 1).

The analysis of the elemental composition of the obtained films, determined from the energy dispersive X-ray (EDS) spectra, indicates the formation of a tungsten oxide compound. EDS spectra (not presented here) recorded in bright and dark zones of SEM images show that bright zones are tungsten rich areas.

3.2. Optical and Electronic Properties. The PA amplitude as a function of photon energy recorded at $17 \mathrm{~Hz}$ for the different $\mathrm{WO}_{3}$ layers is shown in Figure 3. Based on the RG theory [18], the interpretation of the PA signal depends on relation between the thermal diffusion length of samples under study and its thickness. In order to check this point, we determined the thermal diffusivity $(\alpha)$ by PTR technique by fitting a theoretical model to experimental amplitude and phase data as a function of the light modulation frequency, $f$. For calculations, we considered a sample substrate model based on RG theory, where one of these layers is the $\mathrm{WO}_{3}$ thin film of thickness $L$, thermal effusivity $e_{1}$, and optical absorption coefficient $\beta$ and the other layer, a substrate (glass), is transparent to the laser source wavelength and thermally thick in the frequency range used.

The oscillating component of the temperature of the illuminated face of the sample is given by [18] 

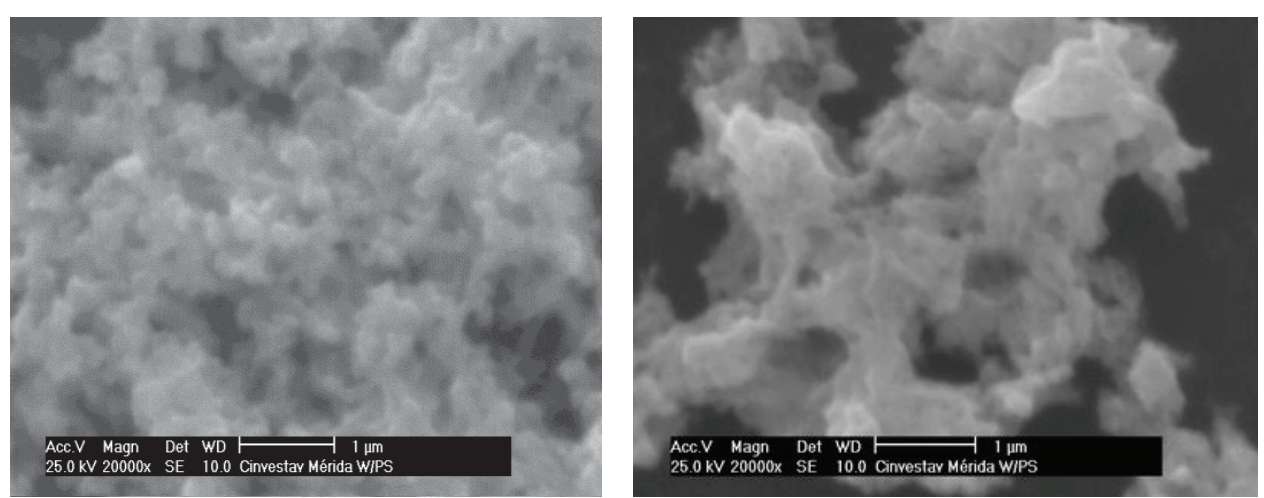

(a)
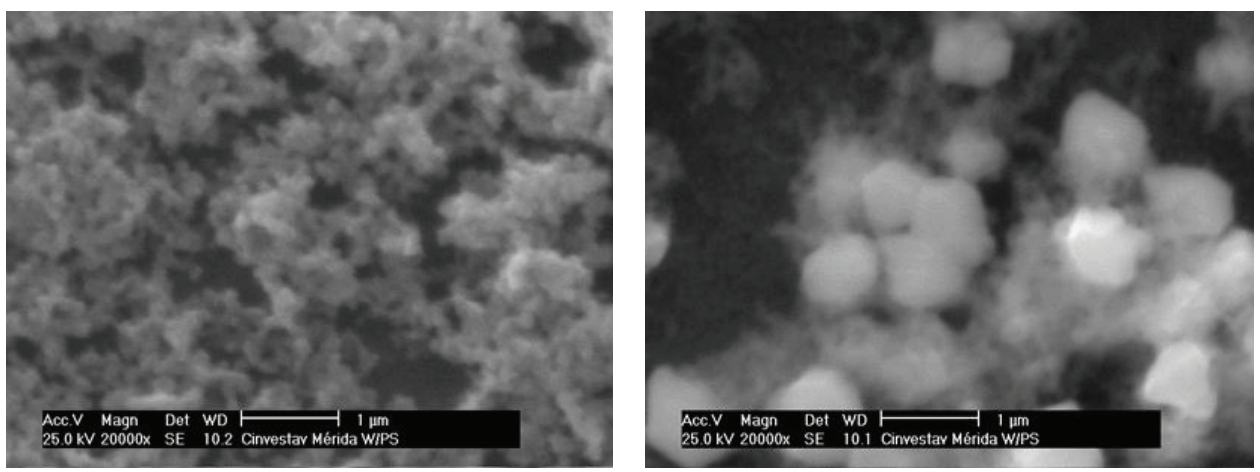

(b)

FIGURE 2: SEM images of (a) $\mathrm{WO}_{3}$ thin film obtained using polystyrene spheres of $0.1 \mu \mathrm{m}$ and (b) polystyrene spheres of $0.5 \mu \mathrm{m}$, before and after annealing at $500^{\circ} \mathrm{C}$.

$$
T(0, f)=\frac{I_{0} \beta(1-R)}{2 k\left(\beta^{2}-\sigma^{2}\right)} \frac{(r-1)\left(b_{12}+1\right) e^{\sigma L}+(r+1)\left(b_{12}-1\right) e^{-\sigma L}-2\left(r b_{12}-1\right) e^{-\beta L}}{\left(b_{12}+1\right) e^{\sigma L}-\left(b_{12}-1\right) e^{-\sigma L}},
$$

where $I_{0}$ represents the light intensity, $b_{12}=e_{1} / e_{2}, r=\beta / \sigma$, $e_{1}=e_{\text {sample }}, e_{2}=e_{\text {glass }}$, and $\sigma=(1+i) \sqrt{\pi f / \alpha}$.

Figure 4 shows PTR amplitude and phase frequency scan of typical $\mathrm{WO}_{3}$ sample. The line represents the best fit using (1) for amplitude and phase data simultaneously. As adjustable parameters in the fitting procedure $\alpha$ and $b_{12}$ were used. The obtained thermal diffusivities for samples A, B, and $C$ were $1.36,1.17$, and $1.13 \times 10^{-4} \mathrm{~cm}^{2} / \mathrm{s}$, respectively. As can be observed, the compact sample showed higher thermal diffusivity, and as the pore size increases, this value is reduced. It has been known that the thermal parameters are affected by many factors as porosity, pore size, and pore shape of materials. In an indirect way, thermal diffusivity along with morphology gives indication about the porosity in our layers.

Calculating the thermal diffusion length $(\mu)$, at the chopping frequency $f$, by the expression $\mu=\sqrt{\alpha / \pi f}$, and using the previous obtained values of $\alpha$, we determined $\mu$ around $200 \mu \mathrm{m}$. This value is much higher than the sample thickness. Additionally, the absorption coefficient at near the band edge for $\mathrm{WO}_{3}$ samples is about $10^{6} \mathrm{~m}^{-1}$; hence, the optical penetration length is about a micron [13]. In this case, the PA measurements were performed under thermally thin condition, and the PA signal was proportional to the product of absorption coefficient and sample thickness.

In Figure 3, it can be observed that, irrespective of sample characteristics, all spectra show singular behavior with the well-defined absorption band and a subsequent increase of PA amplitude for higher energies. According to the peak position of this band, we identified it as originating from the indirect transition. The inset shows the band gap value $(3.17 \mathrm{eV})$ determined by differentiation of PA absorption spectra respect to the photon energy, which does not depend on sample morphology [19]. The reported band gap for bulk $\mathrm{WO}_{3}$ is $2.6 \mathrm{eV}$, and for sol-gel derived nanocrystalline $\mathrm{WO}_{3}$ films the variation of absorption edge for indirect optical transition has been reported in the range of $2.6-3.2 \mathrm{eV}$ [1]. If we consider that the average size of crystallite is about $20 \mathrm{~nm}$, which is comparable with the Bohr radius for $\mathrm{WO}_{3}$ system $(\sim 13 \mathrm{~nm})$, we can assume the presence of weak quantum confinement regimen which led to the higher band gap value 


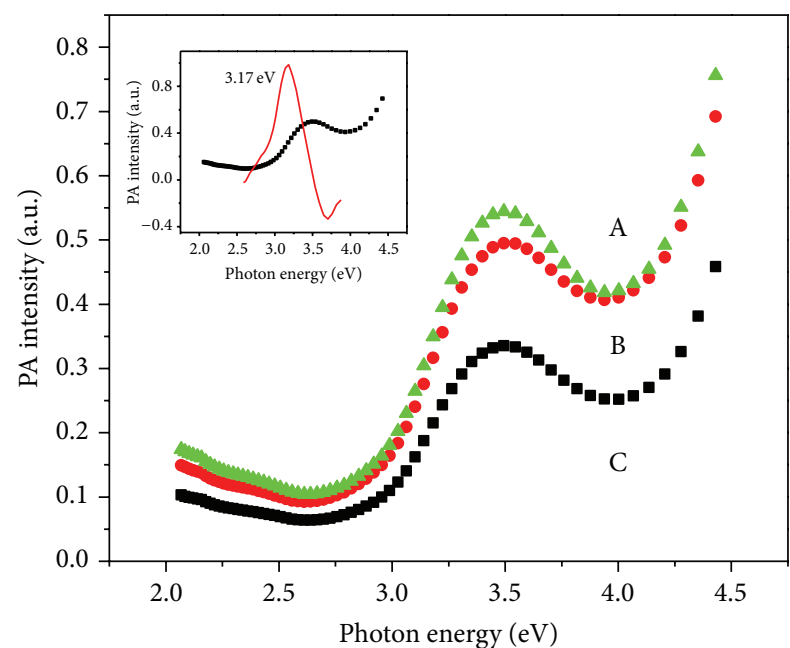

FIgURE 3: The PAS spectra of typical sol-gel sample (A) compared with that which showed porous structure (samples B and C) recorded at $17 \mathrm{~Hz}$. The inset depicts the first derivative (red line) of the PA spectra of sample B.

in our case. We suggest that further increase of PA amplitude is due to a higher energy absorption edge corresponding to direct transition. The observation of high energy transitions by optical transmission spectroscopy is very difficult because in this spectral region the absorption coefficient is very high, and the signal is attenuated over a distance inside the sample [20]. However, in our case, this has been possible using the photoacoustic method and very thin samples.

In addition, it can be noticed in Figure 3 that the photoacoustic response is higher for the $\mathrm{WO}_{3}$ films obtained by the pure sol-gel method (sample A) than for those obtained by sol-gel and templating method (B and $\mathrm{C}$ ) due to higher effective light absorption. The $\mathrm{WO}_{3}$ thin film with bigger pore size (sample C) shows weaker PA response.

Photoluminescence spectra obtained at $15 \mathrm{~K}$ from three samples with different morphologies are shown in Figure 5, where a broad feature in the blue region dominates the PL spectra. It is important to note that, although $\mathrm{WO}_{3}$ is an indirect band gap semiconductor and that it is supposed to have very low emission efficiency, there are several reports in the literature on measurements in $\mathrm{WO}_{3}$ nanoscale materials. In general, two PL emissions have been reported, namely, ultraviolet and blue [14, 21]. The former has been attributed to quantum confinement effects (band-to-band transition) and the second one to oxygen vacancies or defects [22,23].

The shapes of our spectra (see Figure 5) suggest the presence of more than one transition. These emission energies were determined by Gaussian deconvolution. The obtained peak energy positions were around 2.93 and $2.57 \mathrm{eV}$, labeled as high energy (HE) and low energy (LE) peaks, respectively. As it can be seen, the change in the shape of the spectra can be attributed to the change in contributions (intensities) of two transitions, which depends on sample morphology. It is observed that the relative intensity of HE peak decreased with the increase of the pore diameter. We associated HE emission with oxygen vacancies which are commonly present in oxide samples. In order to confirm this hypothesis, we measured the PL spectra of as-grown $\mathrm{WO}_{3}$ thin film without annealing. Compared with annealed samples, the positions of the HE peak appears similar, but the intensity of this band in nonannealed sample is 3 times higher, thus demonstrating our speculation. We thought that after annealing in ambient atmosphere, the diffused oxygen inside the sample led to a reduced oxygen vacancies density and less intensive emission of HE peak in annealed samples. This process is more efficient in samples with wider pores, and consequently, the intensity of HE peak appears weaker for sample C. Another point that we must take into account is the influence of surface defects, whose density is bigger in porous layers where the surface-to-volume ratio increases. If we associate the LE emissions $(2.52 \mathrm{eV})$ with surface defects contribution, as pore size increases, it results in the increase of surface defects density with the consequent increase of LE peak intensity. The relative intensity ratios (HE/LE) were calculated from each PL spectra. The following values were obtained: 1.14, 0.89, and 0.56 for $\mathrm{A}, \mathrm{B}$, and $\mathrm{C}$ samples, respectively. Taking into account potential application of $\mathrm{WO}_{3}$ macroporous materials, samples with less surface defects will be a better option in order to reduce nondesirable recombination. However, comparing our samples with two pore sizes (samples B and C), we can observe that the one with smaller pore size (sample B) exhibits higher PL peak associated to oxygen vacancies. Therefore, for certain applications, the further increase of the pore size is limited by the behaviors of these recombination centers.

3.3. Photocurrent Curves. In order to correlate the electronic properties of these $\mathrm{WO}_{3}$ layers with their performance as photoanodes, photoelectrochemical analyses were carried out. Figure 6 compares photocurrent potential curves for porous and compact tungsten oxide thin films. It is clear that for the $\mathrm{WO}_{3}$ thin films without addition of PS spheres, the measured anodic current was the smallest, while it was significantly enhanced for the $\mathrm{WO}_{3}$ with $0.5 \mu \mathrm{m}$ of PS. On the other hand, by increasing the potential up to $1.0 \mathrm{~V}$, the photocurrent increased sharply for films with $0.5 \mu \mathrm{m}$ of PS.

This picture correlates well with the morphology of the samples and PL results. The sample $\mathrm{C}$ shows bigger pores and lower oxygen vacancy density after annealing, as was mentioned before. This diminution of recombination centers causes the lowest electron-hole recombination rate and consequently the improvement of photon-to-electron conversion efficiency. Similar results have also been reported for the $\mathrm{WO}_{3}$ photoanodes by different authors $[2,24]$, where a template strategy facilitated charge exchange on the surface enhancing the photocurrent density.

\section{Conclusions}

Tungsten oxides thin films with two different pore sizes were grown by sol-gel technique using polystyrene microspheres as a template. The PA characterization reveals the same absorption edge value irrespective of sample morphology, 


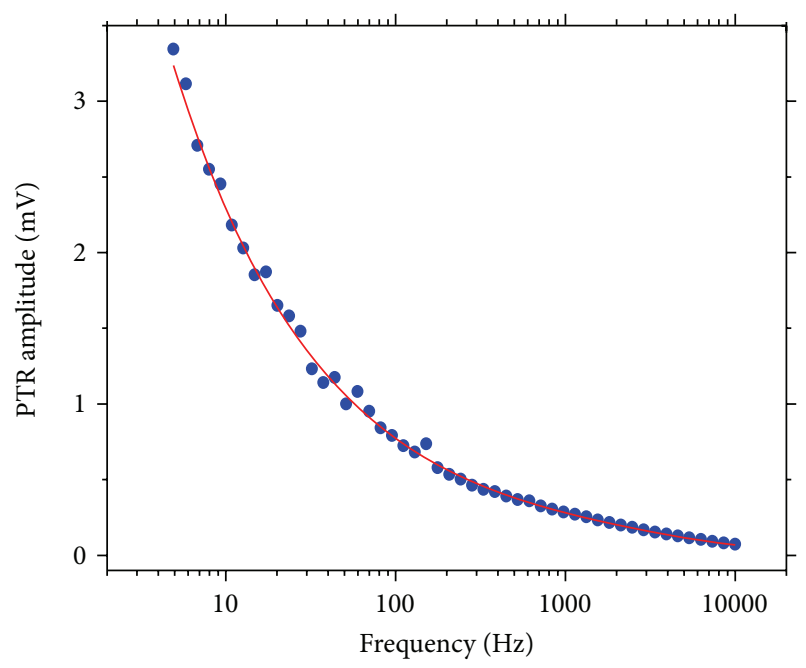

(a)

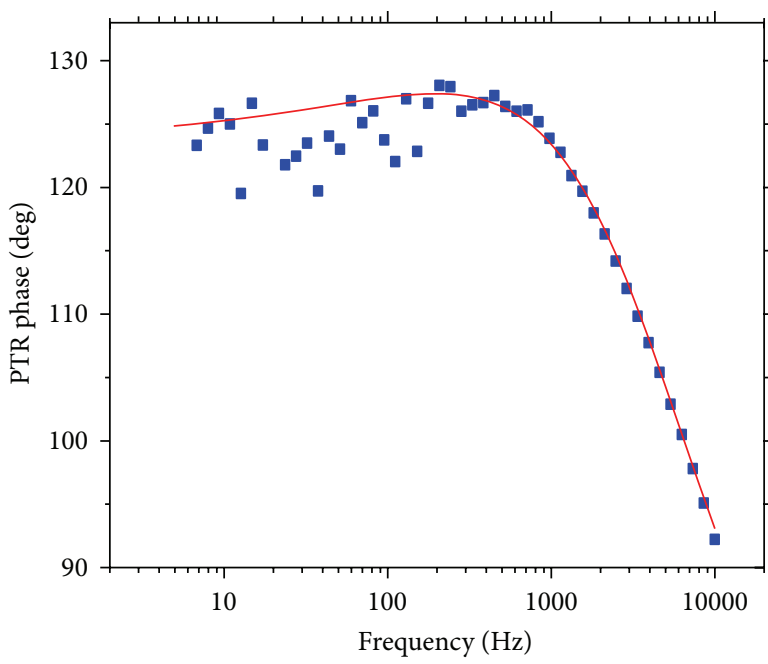

(b)

FIGURE 4: PTR amplitude and phase frequency scan of representative sample. The red line represents the best fit using (1).
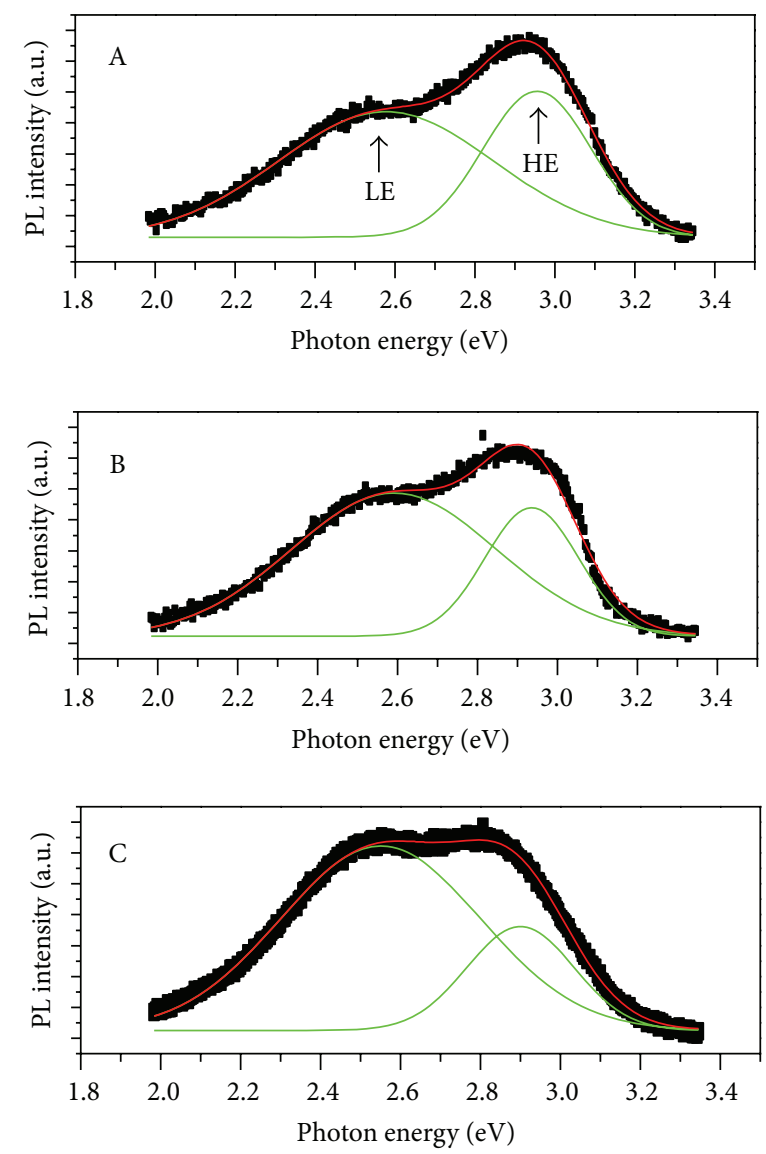

FIGURE 5: PL spectra of $\mathrm{WO}_{3}$ thin films with different morphologies acquired at $15 \mathrm{~K}$.

while the amplitude response decreases for bigger pore size due to the sample effective light absorption. We identified the resulting optical transition around $3.17 \mathrm{eV}$ as an indirect transition, in agreement with the previously reported values for $\mathrm{WO}_{3}$ thin films. The PL measurements revealed broad emission band in the blue region for thin films prepared with PS spheres of 0.1 and $0.5 \mu \mathrm{m}$ diameter and the compact layer. The deconvolution of the emission band showed two transitions, which were associated with two factors: the decrease of oxygen vacancies and the increase of surface defects as 


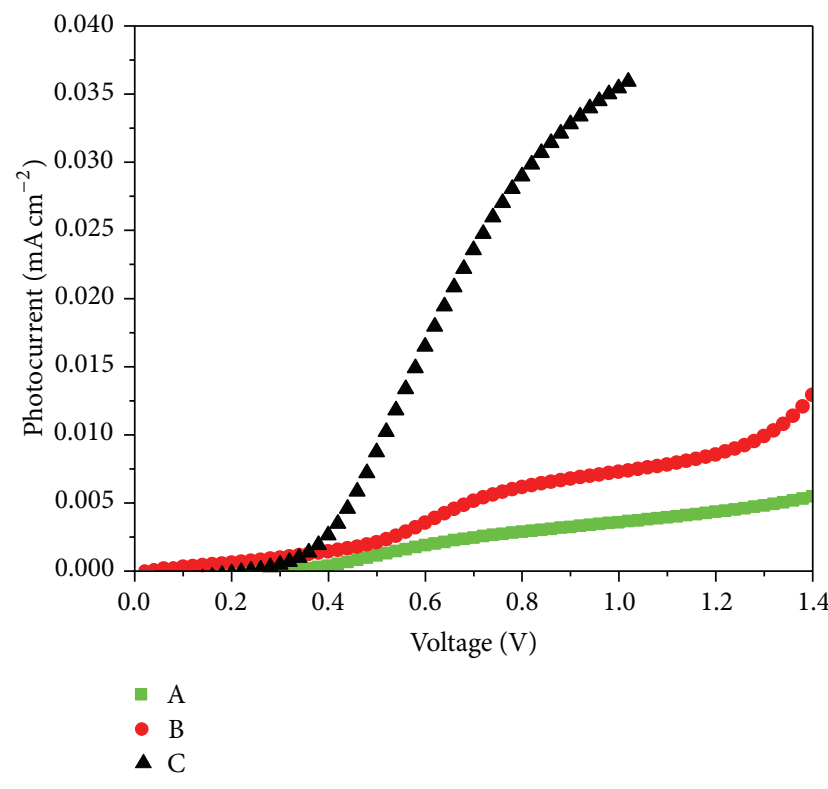

FIgURE 6: Photocurrent potential curves for compact (A) and porous $(\mathrm{B}, \mathrm{C})$ tungsten oxide thin films.

pore size increases. Increasing pore size up to $0.5 \mu \mathrm{m}$, a better photocurrent response was obtained compared with the other samples.

\section{Acknowledgments}

The authors want to thank D. Aguilar and M. Rodríguez for their assistance in XRD and J-V measurements. E. Marín thanks the support of CONACyT, SIP-IPN (Grant 1491), and COFAA-IPN. U. Nogal is also greatly acknowledged for his help with PAS measurements.

\section{References}

[1] M. Deepa, A. K. Srivastava, M. Kar, and S. A. Agnihotry, "A case study of optical properties and structure of sol-gel derived nanocrystalline electrochromic $\mathrm{WO}_{3}$ films," Journal of Physics D, vol. 39, no. 9, pp. 1885-1893, 2006.

[2] S. Berger, H. Tsuchiya, A. Ghicov, and P. Schmuki, "High photocurrent conversion efficiency in self-organized porous $\mathrm{WO}_{3}$," Applied Physics Letters, vol. 88, no. 20, Article ID 203119, 3 pages, 2006.

[3] S. Badilescu and P. V. Ashrit, "Study of sol-gel prepared nanostructured $\mathrm{WO}_{3}$ thin films and composites for electrochromic applications," Solid State Ionics, vol. 158, no. 1-2, pp. 187-197, 2003.

[4] Y. Djaoued, P. V. Ashrit, S. Badilescu, and R. Brüning, "Synthesis and characterization of macroporous tungsten oxide films for electrochromic application," Journal of Sol-Gel Science and Technology, vol. 28, no. 2, pp. 235-244, 2003.

[5] E. O. Zayim, P. Liu, S.-H. Lee et al., "Mesoporous sol-gel $\mathrm{WO}_{3}$ thin films via poly(styrene-co-allyl-alcohol) copolymer templates," Solid State Ionics, vol. 165, no. 1-4, pp. 65-72, 2003.
[6] L. Yang, D. Ge, J. Zhao, Y. Ding, X. Kong, and Y. Li, "Improved electrochromic performance of ordered macroporous tungsten oxide films for IR electrochromic device," Solar Energy Materials and Solar Cells, vol. 100, pp. 251-257, 2012.

[7] M. D’Arienzo, L. Armelao, C. M. Mari et al., "Macroporous $\mathrm{WO}_{3}$ thin films active in $\mathrm{NH}_{3}$ sensing: role of the hosted $\mathrm{Cr}$ isolated centers and Pt nanoclusters," Journal of the American Chemical Society, vol. 133, no. 14, pp. 5296-5304, 2011.

[8] M. Sadakane, K. Sasaki, H. Kunioku, B. Ohtani, R. Abe, and W. Ueda, "Preparation of 3-D ordered macroporous tungsten oxides and nano-crystalline particulate tungsten oxides using a colloidal crystal template method, and their structural characterization and application as photocatalysts under visible light irradiation," Journal of Materials Chemistry, vol. 20, no. 9, pp. 1811-1818, 2010.

[9] E. Özkan and F. Z. Tepehan, "Optical and structural characteristics of sol-gel-deposited tungsten oxide and vanadium-doped tungsten oxide films," Solar Energy Materials and Solar Cells, vol. 68, no. 3-4, pp. 265-277, 2001.

[10] P. Tägtström and U. Jansson, "Chemical vapour deposition of epitaxial $\mathrm{WO}_{3}$ films," Thin Solid Films, vol. 352, no. 1-2, pp. 107113, 1999.

[11] L. J. LeGore, O. D. Greenwood, J. W. Paulus, D. J. Frankel, and R. J. Lad, "Controlled growth of $\mathrm{WO}_{3}$ films," Journal of Vacuum Science and Technology A, vol. 15, no. 3, pp. 1223-1228, 1997.

[12] P. P. González-Borrero, F. Sato, A. N. Medina et al., "Optical band-gap determination of nanostructured $\mathrm{WO}_{3}$ film," Applied Physics Letters, vol. 96, no. 6, Article ID 061909, 2010.

[13] I. Gaied, S. Dabbous, T. Ben Nasrallah, and N. Yacoubi, "Investigation of thermal and optical properties of thin $\mathrm{WO}_{3}$ films by the photothermal deflection technique," Journal of Physics: Conference Series, vol. 214, Article ID 012112, 5 pages, 2010.

[14] M. Feng, A. L. Pan, H. R. Zhang et al., "Strong photoluminescence of nanostructured crystalline tungsten oxide thin films," Applied Physics Letters, vol. 86, no. 14, Article ID 141901, 3 pages, 2005.

[15] C. Parachini and G. Schianchi, "Luminescence of $\mathrm{WO}_{3}$ ", Physics Status Solidi A, vol. 72, no. 2, pp. K129-KK132, 1982.

[16] Joint Committee on Powder Diffraction Standards, "Powder diffraction file," Cards 431035, 060416, and 360101, ASTM, Philadelphia, Pa, USA, 1967.

[17] E. Bertaud, International Tables for X-Ray Crystallography, vol. 318, Kynoch Press, Birmingham, UK, 1968.

[18] A. Rosencwaig and A. Gersho, "Theory of the photoacoustic effect with solids," Journal of Applied Physics, vol. 47, no. 1, pp. 64-69, 1976.

[19] R. E. Marotti, D. N. Guerra, C. Bello, G. Machado, and E. A. Dalchiele, "Bandgap energy tuning of electrochemically grown $\mathrm{ZnO}$ thin films by thickness and electrodeposition potential," Solar Energy Materials and Solar Cells, vol. 82, no. 1-2, pp. 85103, 2004.

[20] J. I. Pankove, Optical Processes in Semiconductors, Dover Publications, New York, NY, USA, 1971.

[21] K. Hong, M. Xie, R. Hu, and H. Wu, "Synthesizing tungsten oxide nanowires by a thermal evaporation method," Applied Physics Letters, vol. 90, no. 17, Article ID 173121, 3 pages, 2007.

[22] C.-Y. Su, H.-C. Lin, T.-K. Yang, and C.-K. Lin, "Structure and optical properties of tungsten oxide nanomaterials prepared by a modified plasma arc gas condensation technique," Journal of Nanoparticle Research, vol. 12, no. 5, pp. 1755-1763, 2010. 
[23] B. A. Hernandez-Sanchez, T. J. Boyle, H. D. Pratt III, M. A. Rodriguez, L. N. Brewer, and D. R. Dunphy, "Morphological and phase controlled tungsten based nanoparticles: synthesis and characterization of scheelite, wolframite, and oxide nanomaterials," Chemistry of Materials, vol. 20, no. 21, pp. 66436656,2008

[24] N. Naseri, S. Yousefzadeh, E. Daryaei, and A. Z. Moshfegh, "Photoresponse and $\mathrm{H}_{2}$ production of topographically controlled PEG assisted Sol-gel $\mathrm{WO}_{3}$ nanocrystalline thin films," International Journal of Hydrogen Energy, vol. 36, no. 21, pp. 13461-13472, 2011. 

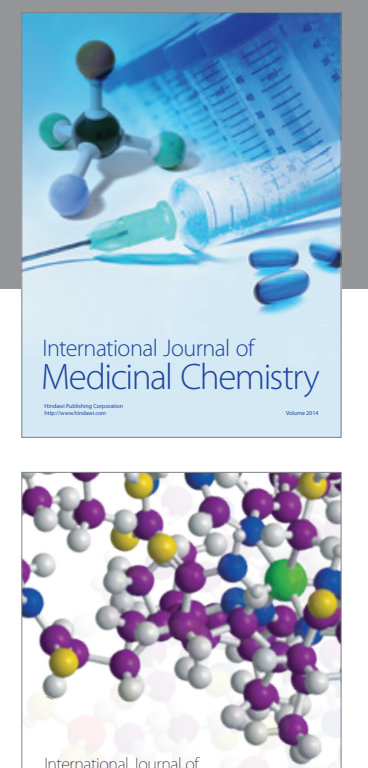

\section{Carbohydrate} Chemistry

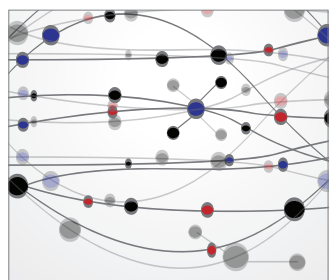

The Scientific World Journal
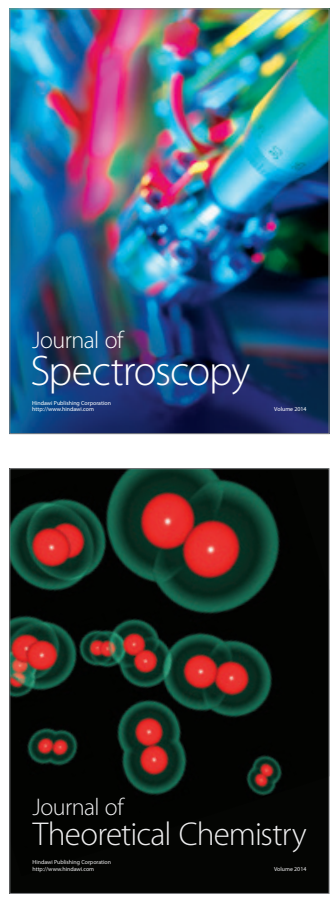
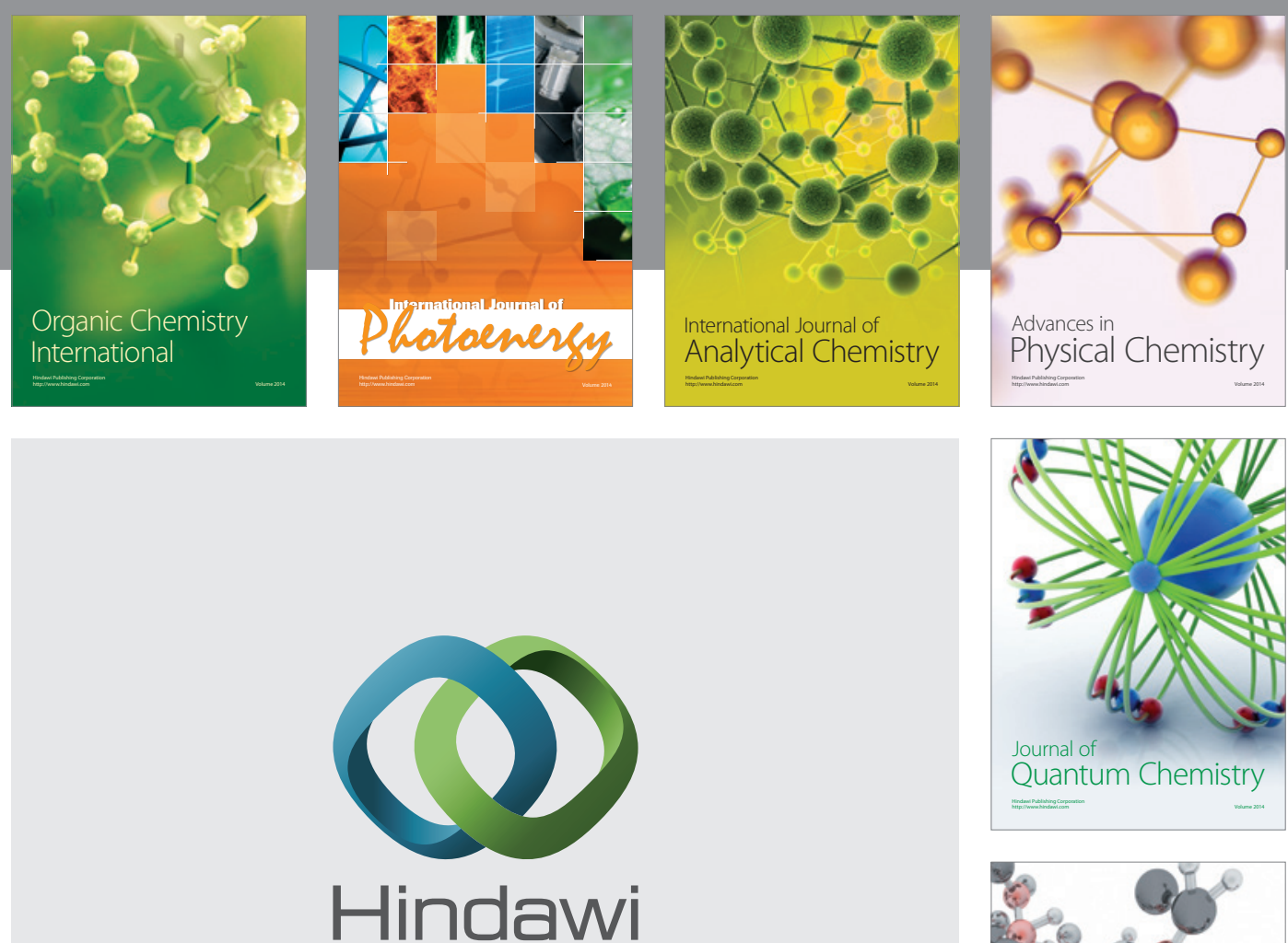

Submit your manuscripts at

http://www.hindawi.com

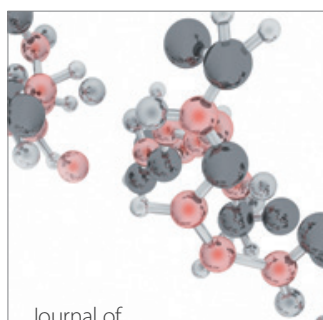

Analytical Methods

in Chemistry

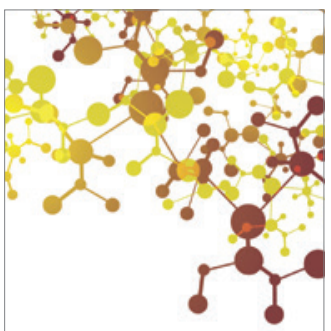

Journal of

Applied Chemistry

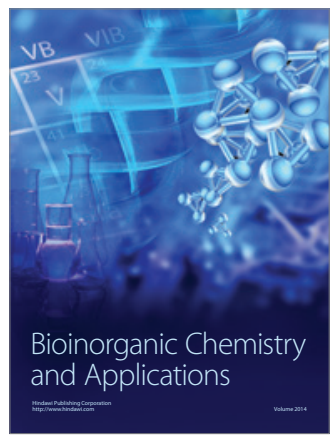

Inorganic Chemistry
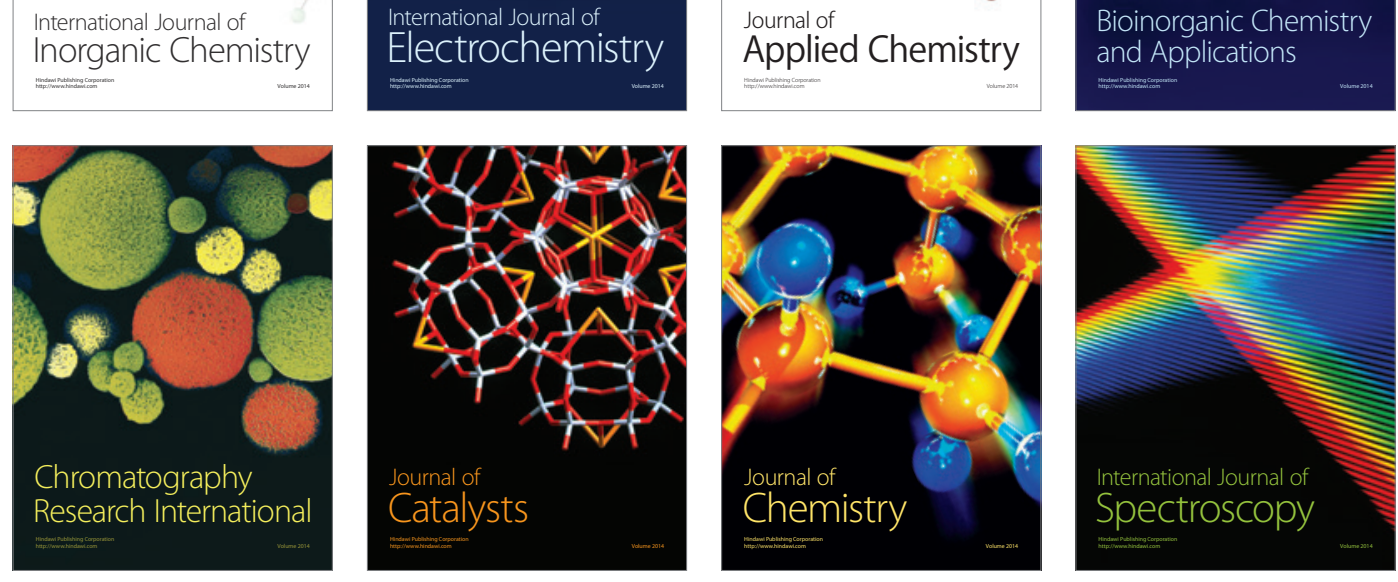